\title{
Stres in Manager Activities
}

\section{Lubos Socha ${ }^{1}, V$ eronika Boldiova ${ }^{1 *}$, Alica Tobisova $^{1}$, Stanislav Kusmirek ${ }^{2}$}

\author{
${ }^{1}$ Department of Air Transport Management, Faculty of Aeronautics, Technical University of Kosice, Kosice, \\ Slovak Republic \\ ${ }^{2}$ Department of Air Transport, Faculty of Transportation Sciences, Czech Technical University in Prague, Prague, \\ Czech Republic
}

*Corresponding author: Technical University of Kosice, Faculty of Aeronautics, Department of Air Transport Management, Rampova 7, 04112 Koice, Slovak Republic, Email: veronika.boldiova@tuke.sk

\begin{abstract}
The article presents and clarifies the topic that was focused on the influence of stress factors in the manger's activity. The subject of the evaluation was the impact of stress on the work and performance of managers. Using the methods we used, we learned about whether stress is a daily part of the managerial position from the point of view of the managers themselves. Furthermore, we are dealing with the issue of the extent to which stressful situations affect the quality and efficiency of the work of managers and we are looking for the main causes of stress in the manager's work. At the same time, we address the possibilities of managing stress, eliminating stress in the work environment, and streamlining workflows in the form of stress stimuli. Last but not least, we have focused on identifying the level of management stress management to support the management of the stresses in organizations where individual managers operate.
\end{abstract}

Keywords

Manager - Stress - Stress management - Stressful situations - Stressors

\section{Introduction}

Recently, we have been experiencing increasingly frequent discussions of work-related stress, whether in the media or in various scientific studies or surveys. The pressure and tension that ultimately results in a stressful situation are experienced by people in all areas of life, but especially in the position of the manager. They regularly face problems, challenges, and situations where effective, creative, and innovative solutions are expected. It is in this direction that stress can play a big role in the work of the managers themselves and thus influence the overall quality of their work [1,2].

The perception and management of stress is highly individual. In general, however, it is known that some people are doing just in stressful situations when they can do the best performance under pressure. However, everything positives also pose a negative, so with a moti- vation in the form of stress comes some risk. Many people, however, perceive stress rather as a de-motivating stimulus that can often increase the speed of their work, but the quality itself and the creativity of thinking may be endangered. If stress is a constant part of the work environment, there is an increased risk of illness, mental health and productivity in the form of increased employee incapacity and fluctuation $[1,2]$. The cost of stress from work environments hinges on employers.

In 2002, based on the European Commission's calculations, the cost of work-related stress has climbed up to $€ 20$ billion a year in Europe. In 2013, however, this amount increased to $€ 617$ billion a year. In total, they accounted for the costs of absenteeism at work of $€ 272$ billion, a loss of productivity totaling $€ 242$ billion, health care employing 63 billion euros of employers, and 39 billion euros in disability payments. In non-European countries, the cost of stress in the work environment is 
similar. For example, in Australia, where an Econtech survey was conducted in 2008 to 2009, based on the estimated costs associated with psychosomatic workplace risks. The cost of work-related stress and absenteeism is estimated at 14.81 billion Australian dollars a year [3].

The activity of the manager as we see has much to do with the prosperity of the business. The main reason why this position in companies is so important and key is that managers are involved in creating a work environment and stimulating employees for better performance. If a manager gets into a stressful situation or suffers from constant stress, it can negatively reflect on the results and performance of the whole working group or even the prosperity of the whole organization [4].

In Norway, a study was conducted that focused on incentives that cause the greatest stress burden on managers. They took into account stressful impulses such as time-span, emotional tension, conflicts between managers and top management or employees, and also the disharmony between work and personal life. Based on this research, they identified the most important sources of stress [5]:

- the work itself (requirements for the manager and the performance of his / her work by the employer),

- the manager's response to stress stimuli and specific situations (for example anger, exhaustion, failure),

- as a manager, he / she manages challenging tasks and situations that place him / herself in great demand ( for example he works harder, works overtime or takes home homework)

- conflicts between work life, family, and personal activities.

\section{Requirements for Managers in Coping with Stress Situations}

Today's requirements for managers are different from those demanded in the past. The reason is the everexpanding trade market as well as the rapidly evolving dynamic environment in which we are located. Today it is not enough for a quality manager to have only the knowledge and skills of a mechanical and technical direction, but on the contrary, his personality traits, qualities and abilities contribute to the perception of crisis situations in a broader context and the ability to deal with them.

In an effort to cope with the stressful situation or incentives that trigger stress, it is extremely important to learn how to manage processes in new, innovative ways. Responding to such incentives is usually a feeling of uncertainty, which in most cases stems from a lack of information, which is one of the main causes of stress. However, if we try to make the problem that stresses us, to make it simpler, to reduce its complexity, it will help us to manage the situation more effectively. It is the manager who is given the "special abilities" that guides in this case, manages processes as well as people - workers and gives information about who, what, when and how to do it $[1,2,4]$.

\subsection{Work Requirements}

It is long enough not only to know how to "command" who has something to do, even if it is art, to know correctly to make a request to do some activity. Increasingly, however, trend managers are becoming more and more " "Complementary" capabilities. Some may be genetically engineered, but if the manager is educated, he / she increases his / her management knowledge, there is nothing that can not be learned and learned. Working requirements for current and successful manager include:

- the ability to see wider contexts or so "Broad outlook",

- the ability to lead and direct a team of people,

- know how to delegate tasks,

- know how to work with time management,

- know how to adapt to new conditions and changes,

- ability to deliver innovative solutions,

- Be determined to continually improve and advance,

- pay attention to self-education,

- know how to think in "big" but watch out for details.

\subsection{Personality Requirements}

If the phrase "successful manager" is spoken, one can imagine someone who has their emotions as anger, frustration, or stress under control and does not let these factors affect his team, no matter what the big problem they are facing. Someone who fully trusts their team of people listens to their opinions and helps increase their potential in each of them, but nevertheless manages successfully, allocates tasks and plans. This is what we can call the quality of a manager with a high emotional intelligence. For managers, this component of their personality is essential in the pursuit of success. According to the american psychologist Daniel Goleman, there are five main elements of emotional intelligence:

Self-awareness - based on that, you always know how you feel and know how your emotions affect people around you. In the lead position, it also means that you have a clear picture of your strengths and weaknesses, which are why you can better understand how to behave, act and manage it more effectively in a stressful situation.

Self-regulation - leaders who can manage themselves effectively rarely when they act quickly or under the influence of negative emotions. This element 




Figure 1. Triangle of managerial stress [?]

of emotional intelligence also includes the flexibility of the leader as well as the sense of personal responsibility.

Motivation - this component represents continuous progress and goals. It also includes the need for a high standard of quality for managerial work.

Empathy - a often highlighted feature that should be available to managers. It is a key component in trying to lead and manage a successful team of people or organization. This helps managers to help develop the potential of their people, provide constructive feedback, and listen to those who need it.

Social skills - managers who have good social skills are also good at managing people and resolving conflicts in a diplomatic way. They are open and willing to hear good news as well as criticism and behave like an example to others.

All the aforementioned work and personality requirements for the manager play a major role in its successful management of stressful situations. If we add to it the capabilities it has and the responses to the burdens, it is a system that experts have called a "triangle of management stress" (see Fig. 1).

\section{Questionnaire Survey of Stress Impact on the Manager's Activity}

Based on the above studies, we conducted a survey to assess the impact of stress on managers' performance. In the first place, we evaluated the extent to which the management work was stressful. We also looked at whether managers themselves considered stress to be a common phenomenon at performance of your work. We also investigated whether the performance of managers is influenced by stress stimuli and to what depths. Consequently, we also focused on the question of how stress managers perceive themselves, but how they try to eliminate it, whether in work itself or in personal life. In addition to these primary objectives, partial objectives were set as follows:
- Identify the main reasons for stress in the manager's activities

- Identify the impact of stress on managers' health

- Whether the issue of stress in the work environment is considered by managers as important

- Whether it affects stress in personal life managerial skills,

- whether the stress management is in the organizations in which they operate

In order to achieve the set goals, a questionnaire was produced, which was placed at the website and at the same time on the social network, because of the better accessibility for the respondents. The questionnaire survey was attended by 60 managers from more than 25 companies active in the Slovak and foreign markets. Of this, $40 \%$ were women and $60 \%$ men. The information gathering process took place over 4 months, namely from December 2016 until March 2017.

The questionnaire survey allowed a deeper insight into the issue of the impact of stress on the manager's activity and at the same time identifying the main stressors that cause managers stressful situations. From our assessment of the impact of stress on management performance, stress is actually considered to be a common part of the work environment, as up to $95 \%$ of managers have this opinion. In the first part of the questionnaire, which asked "Are you always exposed to stressful situations?", was the question of whether managers are exposed to the daily risk of stress in the performance of their work. From the evaluation of the answers, we conclude that most managers are actually exposed to daily stressful situations, and a total of 60 respondents found only one manager who answered, he did not cope with stressful situations on daily basis (see Fig. 2). It is obvious that work related stress takes a relatively large part of the work process and puts some demands on the manager himself in the field of stress management.

So, if we focus on the stressors themselves, that is, what stressors are doing to managers, the questionnaire survey found that they were in-house processes. Most managers, up to $65 \%$ feel stressed especially by excessive



Figure 2. Answers of respondents to the question Are you exposed to stressful situations every day? 
workload, in other words when environmental demands exceed their capabilities.

Nowadays, the trend is to reduce costs, which may take the form of an insufficient number of employees, and so it becomes that managers are responsible for the many tasks and activities that ultimately should be done by somebody else. More than half of the respondents, $55 \%$, feel that. In this case, such shortcomings should be pointed out and eliminated because if the manager is burdened with the amount of work and tasks that could or should be performed by his/her subordinate, the company comes up with the time and quality of the manager's job that the manager should devote to management And managing those business processes that are its primary task. But if there is a lot of staff, the manager can make it easier for them to delegate activities to their subordinates, which save time, utilizes resources, and streamlines overall processes in the organization. Other stressors such as disturbed human relationships with a total of $43 \%$, which are generally very significant to strategic in the work environment, have also been identified.

In the questionnaire survey, only in 15 cases out of a total of 60 interviewed managers said that in organizations where they have established stress management. In this case, it is very important from our point of view the participation of the organization itself, which can help to maintain the so- Healthy workplaces. The team will show the company that it supports its employees, helping to create a stress-free working environment or at least eliminating stress. Because the scale of this problem is really high nowadays, the European Agency for Safety and Health at Work is trying to support this idea through the program called Healthy Workplaces without Stress. It provides a number of practical tools and solutions that help and show businesses that reducing stress is not only possible but also very useful, and can be involved as both organizations and individuals in this campaign. These are tools in the form of practical publications, guidelines, lectures and work tools in assessing workplace stress risk. Organizations also have guidelines on stress management in electronic form available in many languages. The main objective is to provide information, simple explanations and answers to basic questions such as stress in the work environment or what psychosomatic risks are, and to provide assistance in the first steps of employers to address this issue. It also analyzes and helps to understand the effects of stress on the overall functioning of society and provides practical opportunities and ways in which businesses can prevent psychosocial risks at the workplace. They also contain information on legislation, resources and practical tools at national level. Joint efforts and leadership of managers as well as other workers are essential and a culture of working environment can develop with a positive attitude towards addressing stress at the workplace.

In terms of addressing stress situations and attempting to eliminate them, managers say that up to $75 \%$ of them use mainly ways of continuously solving tasks and efficiently using working time. They are also assisted by various sophisticated tools in the form of various software applications, task lists, and comments to help keep their time management and work organized. One of the observed subjects, in the effort to avoid chaos in tasks and responsibilities, makes the most use of the calendar, where it records all the important deadlines and also plans its planned activities into the transparent tables that they determine according to the priorities. That's why she knows exactly when she's supposed to follow, but she also serves as a motivator because she can see exactly what she's worked on and how much work she's done. Key role as manager is also the distribution of tasks and the delegation of powers, which is used by $58 \%$ of the addressed managers. When delegating individual activities, it is also important for the manager to define the strategy in advance, to set goals, to define priorities and, most importantly, to select the right people to solve and fulfill the assigned tasks. By doing so he can avoid working in the form of checking every single step that makes his subordinate, not only that the manager is delaying and burdening, but it also takes him time to relax, which affects his overall performance.

Some respondents question the way they deal with stress in the work environment: "I will slow down my performance to work more efficiently but it has a negative impact on business prosperity," "What I cannot influence, I try not to take so seriously." "Mostly cigarets because I am a smoker."

In an effort to eliminate stress and replenish new energy, the extra-personal life of the manager is very important. This fact is aware of many of them, but finding a balance between private and working life often often looks the most difficult task at all. The key is for managers to ignore the importance of life behind corporate gates. The most important are personal relationships and time spent with family and friends, which help up to $83 \%$ of managers. Sports activities and time devoted to hobbies or hobbies, which $63 \%$ of the interviewed managers are looking for, are also popular. But what is more and more enjoyable is the relaxation technique that $35 \%$ of managers are looking for

\section{Conclusion}

In addition to all the options and efforts to eliminate stress, however, the manager's most important personality is the most important person. He should be aware of himself, of his emotions, but also of reactions to stressful situations, but he should not forget about empathy or understanding. It is these attributes that can help 
to understand the motivation of other people, and this understanding can also lead to a significant reduction of the risk of stressful situations.

When people commit mistakes, the manager should give a helping hand instead of coercion and stress and try to resolve the given situation with understanding. Successful management of stress is perceived above all as an attempt not to push it, but to be aware of the stressors that triggered our reaction. It is also important to set the manager's attitude to the situation, whether perceives it as a disaster (negative stress level) or tries to perceive it as a motivation to find optimal solutions (positive stimulation of the stress burden), gaining experience that increases ability to be able to handle stressful situations. Stress, of course, cannot be completely eliminated from life, but we can practice and try to manage it.

\section{Acknowledgments}

This research was funded by Ministry of Education, Science, Research and Sport of the Slovak Republic within execution of the project No. ITMS 26220220161 cofinanced by EU funds.

\section{References}

[1] R. Sulikova. Psychologia pre manazerov [Psychology for managers]. KARTPRINT, Bratislava, 2012. ISBN 978-80-89553-06-8. (In Slovak).

[2] P. Hartl and H. Hartlova. Psychologicky slovnik [Psychological dictionary]. Portal, Prague, 2000. ISBN 807178303X. (In Czech).

[3] J. Hassard. Calculating the costs of work-related stress and psychosocial risks : literature review. Publications Office, Luxembourg, 2014. ISBN 978-929240-420-8.

[4] M. Szarkova. Psychologia pre manazerov a podnikatelov [Psychology for managers and entrepreneurs]. Sprint, Bratislava, 2007. ISBN 8089085-77-6. (In Slovak).

[5] Wilmar B Schaufeli and Michiel AJ Kompier. Managing job stress in the netherlands. International Journal of Stress Management, 8(1):15-34, 2001. 